\title{
Certification of experts as the cost management tool in the context of increased requirements for construction environmental friendliness
}

\author{
Irina Karakozova, ${ }^{1, *}$ \\ ${ }^{1}$ Moscow State University of Civil Engineering, 26, Yaroslavskoye shosse, 129337, Moscow, Russia
}

\begin{abstract}
The imperfection of the existing approach to holding oral and written examination for the purpose of receiving (extension) the license for preparation of the expert opinion by the applicant (expert) as well as the preparation for passing such an examination can result in the staff deficit in the expert bodies. Since January 1, 2020 the obligatory certification of experts who will sign the expert opinions according to the results of verification of budget documentation is entered. Nowadays, up to the specified date the transition period was determined, when the experts could undergo the certification. The quantity of applicants (experts) who could not pass the examinations, speaks either about the insufficient qualification for execution of these functions, or about the insolvency of the estimated tools, used during the examination. In this regard the main attention is paid to the preparation for examination. Training of applicants (experts) for passing of certification has to be constructed on such principles as relevance, unambiguity, accuracy, orderliness, etc. with the obligatory use of the modern educational technologies. The main stages of training of the applicant (expert) for certification passing are presented in the work. In case of introduction of the offered approach the process of training the applicants (experts) for passing an examination, will certainly allow to increase the importance of the held event, to increase the quantity of the certified experts and also will lead to economy of budgetary funds due to the decrease in unreasonable expenses.
\end{abstract}

\section{Introduction}

In the modern conditions the aspiration of the person to constant perfecting of the accumulated knowledge, skills make up the key to his or her professional body height and also allows to be competitive and independent. The use in practical activities when choosing experts for work in the structural organizations of original positions and requirements of professional standards leads to the fact that the experts have to be focused and motivated on the compliance to the established requirements. Now such requirements are stated in the professional standards which act as characteristic of qualification of the worker for exercise of professional activity of a separate type according to Federal Law No. 236-FZ, dated 03.12.2012 [1]. The structure of the professional standard is approved at the

\footnotetext{
${ }^{*}$ Corresponding author: elena.chibisova_metr@mail.ru
} 
legislative level. It contains the description of labour functions and actions, requirements to education, tutoring, experience of practical work as well as the list of necessary knowledge and abilities [2]. The range of application of the professional standard is rather wide, starting with the employers within the organization activity up to educational institutions of professional education during the development of professional educational programmes [3].

The reform of pricing, undertaken at the moment in the construction industry places great demands for the level of knowledge of the experts which are engaged in drawing up, check or examination of budget documentation, as well as for their qualification. The process of the budget expenses formation which is based on the principles of openness, reliability, accuracy and completeness in the modern conditions demands from participants of this process of constant sharpening of skill and updating of knowledge in the given area. Such approach will promote the increase in professionalism of experts that as a result will allow them to correspond to those competences which are put in professional the standard and are used for assessment of its readiness and ability to professional activity on the basis of the available experiences, knowledge, skills and abilities.

\section{Materials and Methods}

The subject of state examination of the project documentation and results of engineering research include the assessment of the compliance to the requirements of technical regulations, including sanitary and epidemiologic, ecological requirements, to requirements of the state protection of the facilities of cultural heritage, requirements of separate types of safety, for example, fire and also to the results of engineering research. Preparation of the conclusion of state examination is carried out by the persons who acquire the license of preparation of expert reports on the project documentation and/or results of engineering researches by the means of passing of certification (further - the experts).

Except examination of the project documentation and results of engineering research the check of estimated cost which consists in carrying out the analysis and assessment of calculations as a part of the prepared set of budget documentation is carried out. At the same time the used budget standards are compared to those which are included in the federal register of budget standards. It is checked as well the constructive, organizational and technology solutions accepted as a part of the project documentation. At the same time the analysis of size of budget expenses for the purpose of identification not excesses over the cost received in case of application of the integrated cost indexes (standards of the price of construction and standards of the price of constructive decisions) at the same time can be made. It should be noted that nowadays the standards of the price of construction developed in the prices as of 01.01.2017 are used. And the nomenclature of collections rather extensive also includes cost indexes for objects of different function, for example, health care facilities, educations, external networks and constructions of heat supply, etc. At the same time the situation with the standards of the price of constructive decisions is much worse. For the last five years only one collection of standards of the price of constructive decisions "Highways" in the prices for January 01, 2014 was developed.

The statistical data of FAD "Glavgosekspertiza of Russia" obtained as a result of conducting check of reliability of determination of estimated cost of objects which financing happened to attraction of financial resources of the federal budget during 20152018 are provided in Table 1 [4]. 
Table 1. Data on the results of verification of the accuracy of the estimated cost of the facilities.

\begin{tabular}{|l|c|c|c|c|c|}
\hline \multicolumn{1}{|c|}{ Received results } & $\mathbf{2 0 1 5}$ & $\mathbf{2 0 1 6}$ & $\mathbf{2 0 1 7}$ & $\mathbf{2 0 1 8}$ & $\begin{array}{c}\text { 1st half of } \\
\mathbf{2 0 1 9}\end{array}$ \\
\cline { 2 - 6 } & $\begin{array}{c}299.9 \\
\text { billion } \\
\text { rubles }\end{array}$ & $\begin{array}{c}299.9 \\
\text { billion } \\
\text { rubles }\end{array}$ & $\begin{array}{c}299.9 \\
\text { billion } \\
\text { rubles }\end{array}$ & $\begin{array}{c}299.9 \\
\text { billion } \\
\text { rubles }\end{array}$ & $\begin{array}{c}299.9 \text { billion } \\
\text { rubles }\end{array}$ \\
\hline $\begin{array}{l}\text { Economy of the federal funds } \\
\text { according to the results of check } \\
\text { of reliability of estimated cost of } \\
\text { the facilities, financed with the } \\
\text { attraction of financial resources } \\
\text { of the federal budget }\end{array}$ & $18.9 \%$ & $19.6 \%$ & $9 ., 5 \%$ & $8.1 \%$ & $11.2 \%$ \\
\hline $\begin{array}{l}\text { Percent of the decrease in the } \\
\text { estimated cost of a capital } \\
\text { construction project }\end{array}$ & $\begin{array}{l}1049 \\
\text { units }\end{array}$ & $\begin{array}{c}908 \\
\text { units }\end{array}$ & $\begin{array}{c}883 \\
\text { units }\end{array}$ & $\begin{array}{c}875 \\
\text { units }\end{array}$ & $\begin{array}{c}513 \\
\text { units }\end{array}$ \\
\hline $\begin{array}{l}\text { The quantity of the negative } \\
\text { conclusions of state examination } \\
\text { of the project documentation } \\
\text { issued concerning facilities } \\
\text { which technical solutions after } \\
\text { realization could lead to the } \\
\text { emergence of contingency } \\
\text { situations }\end{array}$ & & & & & \\
\hline $\begin{array}{l}\text { In \% to total quantity of the } \\
\text { conclusions of the state } \\
\text { examination of the project } \\
\text { documentation }\end{array}$ & $22 \%$ & $22 \%$ & $24 \%$ & $24 \%$ & $28 \%$ \\
\hline
\end{tabular}

Dynamics of change of the indicators given in table 1 demonstrates the tendency to the increase in the level of the experts participating in check and examinations of estimated cost of capital construction projects.

According to [5] during the verification of reliability of determination of estimated cost treat the main discrepancies and violations to requirements of normative and methodical documentation on pricing and budget rationing;

- discrepancy of forms and structure of budget documentation to requirements of operating normative and methodical documents in the given area;

- incorrect determination of estimated cost, in connection with the shortage of qualified specialists in staff of the design organizations and lack of the corresponding monitoring from the customer regarding completeness and correctness of initial and allowing documentation, terms and the course of realization of design stages and check, the choice and cost of the accepted material resources and an inventory, structure of the separate articles of expenses considered in estimated cost and др;

- absence or incorrect determination of the ceiling price calculated with use of the integrated cost indexes or documentary confirmed information obtained from documentation of the implemented projects analogs regarding a regularity of the choice of the project analog, application of indexes deflators, calculation of the correction factors considering a difference in volumes of a designed project and the project analog, etc.

Current situation confirms the need of perfecting of level of professionalism of the experts participating in conducting examination of all the types of budget documentation as a part of the project documentation, especially in case of financing of works with the attraction of financial resources of the federal budget.

In the middle of 2017 the Ministry of Construction, Housing and Utilities of the Russian Federation approved by the order of June 29, 2017 No. 941/pr. [6] the list of activities of experts on which applicants by results of examination acquire the right of preparation of expert reports on the project documentation and/or results of engineering researches. For 
the experts who are carrying out verification of the section "The Estimate on Construction" the order of the Ministry of Construction, Housing and Utilities of the Russian Federation of September 17, 2018 No. 581/pr. [7] the list of the directions was complemented with the recent trend "Pricing and budget rationing". As a result, today 65 activities of experts are approved. When carrying out expert assessment of technology solutions on the corresponding objects, the constructive decisions considering specific features of projection of such objects the specified directions are obligatory.

For obtaining the right of preparation of expert opinions the examination of the applicant by means of holding oral and written examination is carried out. The order of Ministry of Construction No. 211/pr. accepted on the April 08, 2019 [8] the list of questions for holding an examination in the form of testing and so-called oral examination approved. Among the questions directly related to issues of pricing, the majority falls into to questions, the bound to the estimated cost of construction, with use of estimate norms on different types of works, the integrated standards of cost indexes, with knowledge of structure and structure of the budget regulatory base. Besides, place also organizational issues, the bound to turnkey contracts and order of carrying out technological audit of the investment project [8].

For receiving admission to passing of examinations preliminary qualification which has to confirm presence at the applicant of profile higher education according to the stated activity of the expert, concrete length of service, lack of criminal record is carried out and also the applicant has to live constantly in the Russian Federation [9].

The specified requirements to the expert or the applicant for the right to receive such status and also to process of carrying out certification, not only increase level of responsibility of experts, but also stimulate them to professional development. The first results by results of passing an examination in the Ministry of Construction, Housing and Utilities of the Russian Federation were unfavourable as the qualification certificate of the expert after passing of written and oral examinations was received by no more than $30 \%$ of total number of the participating experts.

Thus, the received results by results of assessment of knowledge of applicants (experts), persons interested to receive (to prolong) the right for preparation of the conclusions of state examination of the project documentation and results of engineering researches and also check of reliability of determination of estimated cost of objects when financing with attraction of financial resources of the federal budget, confirmed need of a pre-treatment of experts to certification passing.

Therefore an objective of this research is development of suggestions for improvement of process of training of the applicant (expert) for passing of certification for receiving positive assessment of knowledge of the applicant for the right of preparation of the conclusions and obtaining the qualification certificate confirming ability of the applicant (expert) to professional activity regarding the checks of reliability of estimated cost of capital construction projects.

\section{Results}

Training of the applicant (expert) for passing of certification for the license of preparation of the conclusion according to the results of check of reliability of estimated cost of capital construction projects has to be based on the following principles:

- relevance, i.e. the information for the preparation for passing of certification has to reflect the existing condition of the legislative, normative-and-technical-and-normative and methodical base of ensuring process of development of the project documentation, preparation of results of engineering researches and determination of reliable estimated cost of construction (reconstruction, overhauling, etc.) capital construction projects; 
- uniqueness, i.e. the obtained information has to provide the unambiguous perception of the necessary data used by applicants (experts) in professional activity;

- accuracy, i.e. the obtained information has to be concretized and detailed in that degree in what operating legal, normative and technical and normative and methodical documents for certification passing allow;

- regularity, i.e. training of applicants (experts) has to represent the complex of the interdependent provisions allowing to systematize the obtained information.

The teachers, who are expressly trained for this purpose having not only a teaching experience, but their experience of works on the direction of tutoring have to be engaged in development of programs of tutoring, tutoring and also carrying out certification.

Before the development of programmes of tutoring for the preparation for certification passing, for example, in the "Pricing and Budget Rationing" direction it is necessary to reveal the main problems of the existing system of the examination of applicants (experts) for the license of obtaining the qualification certificate as well as the opportunity and desire of full participation of the applicants (experts) in the educational process directed to preparation them for the examination.

The main stages of training of the applicant (expert) for passing of the certification are presenyted in Figure 2. They are to contain some actions, directional including those for the definition of methods of carrying out measurements and estimates on the basis of operating legal-and-normative and methodical documents; developments of criteria and rules, preparation of an algorithm of holding examination, development of the system of assessment of knowledge of the examined applicant (expert) and so on.

The main issues of training of applicants (experts) for passing of certification include:

- formation of highly skilled personnel structure;

- inducing of body height of professionalism and level of knowledge of the expert,

- establishment of compliance of experts of a post,

- identification of prospects of use of potential opportunities of experts,

- ensuring differentiation of the amount of compensation of experts taking into account the established qualification category and volume of the performed work after obtaining the qualification certificate by results of examination.

Test tasks where one question may contain several possible answers are widely used nowadays for the development of the system of assessment of knowledge of the examined persons, at the same time not always only one option the answer can be the exact. Such tool of estimated tools as tests, is convenient and simple in the use as they do not demand many participants for their preparation. However, at the same time they also have some of disadvantages, for example, it is impossible to receive confirmations of extent of mastering test material, identifications of actions of the applicant (expert) in practice. It should be also noted that the labor input of preparation of test tasks and their dependence on creative approach of the teacher is considerable [10].

In case of the examination at applicants (experts) to passing of certification on the license of preparation of the conclusion by results of check of reliability of determination of estimated cost of capital construction projects, it is necessary to create such a set of didactic tools which will promote the identification both of knowledge, of the bound to the conceptual framework within the programme of tutoring (a subject, the module, the section, etc.), methods of determination of estimated cost, structure and structure of budget standards, etc., and the ability to develop and make various decisions within the practical activities.

For example, the examination of applicants (experts) after the end of training in a single programme is carried out in two steps. At the first stage to use test materials as a part of which there can be test tasks of the closed form when the correct answer gets out of several options offered at choice or an open form when in the course of the answer to the question 
it is necessary to add a keyword. At the same time, it is possible to use also entertaining tasks in the form of tasks drawings, logical mini-tasks, crossword puzzles. It is possible to carry to the advantage of such tasks "an implicit examination and abilities that positively affects check since on trainees' foreign factors do not prevail, and they are completely liberated at the answer" [11, 12]. At the second stage for check of readiness of the listener for professional activity it is possible to use simulation models, so-called the simulator, created on the basis of real activity in the particular professional sphere.

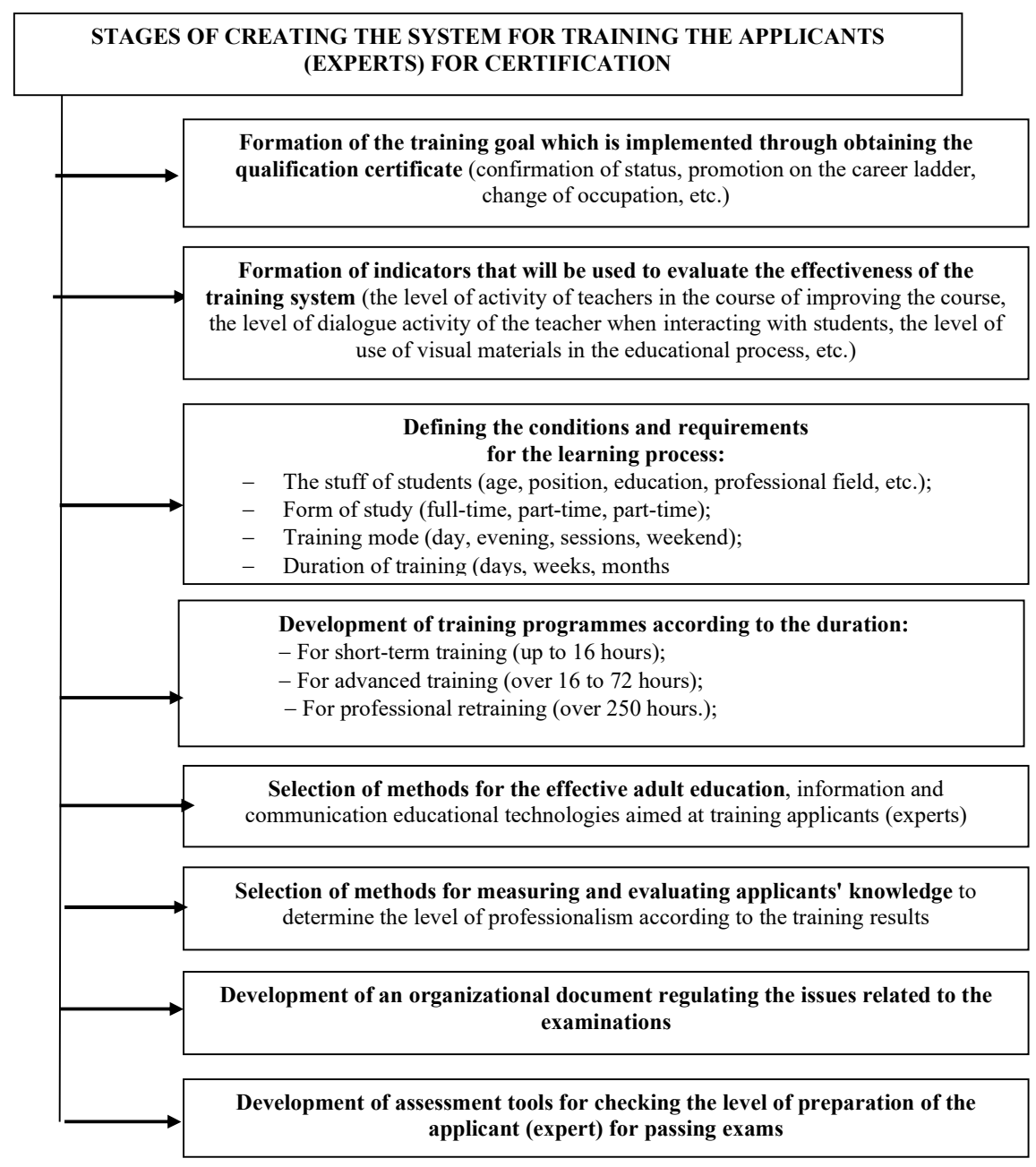

Fig. 1. The main stages of preparing an applicant for the exam.

In the form of exercise machines the first simulation models were used in the military sphere for tutoring of pilots. Today such program simulators rather actively for tutoring and check of the gained knowledge use in medicine, restaurant business, education etc. At the same time the program simulator represents a certain game which promotes determination of the sequence of adoption of the correct decisions in the virtual conditions for obtaining desirable result. It should be noted that it not only interesting and fascinating form of 
education, but also an index of how actions of the person can affect results of activity of the company, work of collective, cooperation with partners etc. [13].

Program simulators also allow to recreate completely the course of real events in real time and to develop an algorithm of actions and also to lower or in general to exclude number of mistakes in practice. It is possible to lower time for preparation for realization of any actions by the means of programs simulators, to holding actions, to predict results from activity, to estimate the level of the gained knowledge and the acquired skills after training, to create ability to make optimal solutions in borders of the considered situation, to carry out self-checking and also to create the culture of cognitive activity [14].

For applicants (experts) in the "Pricing and Budget Rationing" direction it is possible to model various situations, for example, drawing up accounting of structural resources or check of local budget calculations on different types of works. Content of the game on the example of one situation, by the bound to verification of primary budget document (local budget calculation) is specified in Table 2 .

Table 2. Content of the training game.

\begin{tabular}{|c|c|c|}
\hline & Game components & Content of the game \\
\hline 1 & Subject & Budget documentation in construction \\
\hline 2 & Purpose & $\begin{array}{l}\text { Educational element: to create new or to systematize the } \\
\text { available knowledge. } \\
\text { Diagnostic element: to determine the level of development of } \\
\text { the gained or available knowledge for the concrete subject } \\
\text { (situations, etc.) }\end{array}$ \\
\hline 3 & Situation 1 & $\begin{array}{l}\text { Check of local budget calculation on construction works for } \\
\text { roof paving }\end{array}$ \\
\hline 4 & Rules for Situation 1 & $\begin{array}{l}\text { - Definition the quantity of participants. } \\
\text { - Distribution of functions and roles for the task } \\
\text { performance and control of its execution. } \\
\text { - Providing the participant with the necessary sources on } \\
\text { the paper or electronic medium according to the game } \\
\text { subject. } \\
\text { - Introduction of some temporary restrictions for the task } \\
\text { realization. }\end{array}$ \\
\hline 5 & $\begin{array}{l}\text { Course (contents) for } \\
\text { Situation } 1\end{array}$ & $\begin{array}{l}\text { Confirmations of the executed action regularity during the } \\
\text { justification of the choice of separate budget standards for the } \\
\text { used production technology of works; } \\
\text { - The use of correction factors for accounting of conditions } \\
\text { of production of works; } \\
\text { Justification of compliance of principal specifications and } \\
\text { consumption rates of the material resource of the used } \\
\text { production technology of works; } \\
\text { - The use of the current prices of the material resources; } \\
\text { etc. }\end{array}$ \\
\hline 6 & $\begin{array}{l}\text { Actions of the } \\
\text { participants }\end{array}$ & $\begin{array}{l}\text { The sequence of actions is not subject to algorithmization, it is } \\
\text { formed by each participant of the process individually within } \\
\text { the designated situation. }\end{array}$ \\
\hline 7 & Assessment & $\begin{array}{l}\text { It is carried out according to the goals, presented in paragraph } \\
2 \text { of the present table }\end{array}$ \\
\hline 8 & Result & The correct solution according to the objective for Situation 1 \\
\hline
\end{tabular}

Thus, the development and the use in practical activities of programmes simulators on purpose not only tutorings, but also checks of the gained knowledge in the course of tutoring or detection of the need of the increase in education level for constantly changing modern conditions will allow to carry out certification of applicants (experts) for the right 
of preparation of the conclusion by results of check of reliability of determination of estimated cost of capital construction projects on more high level.

\section{Discussion}

The offered approach to training of applicants (experts) for the purpose of receiving by the license for preparation of the conclusion according to the results of check of reliability of the estimated cost of a capital construction project will allow to receive the following results:

- obligatory keeping of the requirements of normative-and-methodical and normativeand-technical documents;

- upgrading of the project documentation by the means of strengthening of check and monitoring from the experts;

- economy of budgetary funds due to the optimization of the made design decisions;

- formation of "the frictionless environment" in interaction of participants of the investment and structural sphere with the expert bodies in the course of preparation and obtaining expert opinions [15];

- the increase in the experts' professionalism for the purpose of compliance to requirements of professional standards $[16,17,18,19,20]$.

\section{Conclusions}

The process of the organization of holding examination for the license tfor the right of preparation of the expert opinion and as well as requirement to applicants (experts) wishing to acquire such right is described in the article. The indicators characterizing activity of the expert bodies supervising issues of pricing in construction are given. Weaknesses of the existing system of certification of applicants (experts) are revealed. On the basis of the carried-out analysis new approach to the organization and holding examination for obtaining the qualification certificate is offered.

Today for preparation for certification and passing a qualification examination the applicant (expert) for the right of receiving (extension) of the status of the expert has to have such qualities as self-organization, discipline, responsibility, commitment. However at the same time the approaches to the organization of process of tutoring, technical and technological support of process of tutoring, engaging to this process of the pedagogical shots having experience in the field of pricing and budget rationing in construction taking place and also professional community of the structural industry have to be changed.

\section{References}

1. Federal Law of the Russian Federation No. 236-FZ of December 03 (2012)

2. Order of the Ministry of Labour and Social Protection of the Russian Federation No. 147n of April 12 (2013)

3. Resolution of the Government of the Russian Federation No. 23 of January 22 (2013)

4. Statistics of FAD "Glavgosekspertiza of Russia", https://gge.ru/analytics/statistika-pogodam/

5. Annual report of FAD "Glavgosekspertiza of Russia" for 2018, https://gge.ru/upload/iblock/95d/Годовой\%20отчет\%202018.pdf 
6. Order of the Ministry of Construction, Housing and Utilities of the Russian Federation of 29.06.2017 No. 941/ave

7. Order of the Ministry of Construction, Housing and Utilities of the Russian Federation of 17.09.2018 No. 581/ave

8. Order of the Ministry of Construction, Housing and Utilities of the Russian Federation of 08.04.2019 No. 211/ave

9. Resolution of the Government of the Russian Federation from 31.03.2012 No. 271

10. Yu.V. Sorokopud, Pedagogics of the higher school (Phoenix, Rostov N/D, 2011)

11. L.I. Fedorova, Game: didactic, role, business. Solution of educational and professional problems (FORUM, Moscow, 2009)

12. A.A. Zubrilin, Standards and monitoring in education 5, 14-19 (2012)

13. V.V. Shoptenko, IHR manager 2, 24-29 (2008)

14. I.A. Kolesnikova, A.E. Maron, E.P. Tonkonogaya, The prionciples of Andragogika (Publishing centre "Akademiya", Moscow, 2007)

15. T. Simankina, I. Kibireva, A. Mottaeva, M. Gusarova, Advances in Intelligent Systems and Computing 983, 138-145 (2019) https://doi.org/10.1007/978-3-030-19868-8_13

16. E.M. Akhmetshin, I.A. Ilyina, V.V. Kulibanova, T.R. Teor, Proceedings of the 2019 IEEE Communication Strategies in Digital Society Seminar, ComSDS 2019, 50-55 (2019) doi:10.1109/COMSDS.2019.8709645

17. A. Mottaeva, J. Ćetković, Advances in Intelligent Systems and Computing 692, 11511159 (2018) doi: 10.1007/978-3-319-70987-1_123

18. E. M. Akhmetshin, Journal of Advanced Research in Law and Economics 8(6), 16841692 (2017) doi:10.14505/jarle.v8.6(28).03

19. D. Khodzhaev, B. Normuminov, Y. Mustapakulov, A. Mottaeva, E3S Web of Conferences 110, 01045 (2019) doi.org/10.1051/e3sconf /201911001045

20. E.M. Akhmetshin, G.N. Larionova, E.V. Lukiyanchina, Y.P. Savitskaya, R.A. Aleshko, O.S. Aleynikova, Journal of Entrepreneurship Education 22 (2019) 